\title{
A New Proposal for Measuring Marital Fertility in Historical Populations
}

\author{
Jesús J. Sánchez-Barricarte \\ Departamento de Sociología \\ Universidad Pública de Navarra \\ Campus Arrosadía \\ 31006 Pamplona (Spain)
}

\begin{abstract}
In this paper, a critical analysis is made of some of the indices used in numerous historical studies on the decline of fertility. More concretely, it is demonstrated how the Total Marital Fertility Rate (TMFR) and the $I_{\mathrm{g}}$ and $I^{\prime}$ g indices of marital fertility designed by Coale (1986) not only are not good indicators of a population's level of marital fertility, but also in some cases (for example, when there is an important delay in female mean age at marriage) can even indicate an increase in marital fertility when in reality it is decreasing. Likewise, a new index for measuring marital fertility (known as the Navarre Index) is presented which takes into account women's average age at marriage as well as their mortality rate during their reproductive period.
\end{abstract}

Key Words: marital fertility, formal demography, historical populations 
Sánchez-Barricarte, $J$.

\section{Résumé}

Dans cet article, une analyse critique est faite sur quelques-uns des indices utilisés dans de nombreuses études historiques concernant la diminution de la fécondité. Plus concrètement, il est démostré comment le Taux de Fécondité Maritale Totale et les indices $I_{\mathrm{g}}$ et $I_{\mathrm{g}}$ de fécondité maritale désignés par Coale (1986) non seulement ne sont pas de bons indicateurs d'un niveau de fécondité maritale de population, mais, dans certains cas (par example, quand il y a un retard important dans l'âge moyen de mariage des femmes), ils peuvent même indiquer une augmentation de la fécondité maritale lorsqu'en réalité il s'agit d'une diminution. Un nouvel indice pour mesurer la fécondité maritale (connu comme l'Indice de Navarre) est aussi présenté, qui prend en considération l'âge moyen de mariage pour les femmes, et, en même temps, leur taux de mortalité pendant leur période reproductive.

Most-clés: fécondité maritale, démographie formale, populations historiques.

\section{Measures of Fertility}

In order to study any demographic reality it is important to define first the indices and rates we plan to use to measure that reality. The aim of demographic inquiry is, first and foremost, the measurement of a phenomenon in a precise manner so that comparisons may be made in an unequivocal way. The traditional measures which have been used to study fertility give us more or less information depending on the quality and refinement of data. Thus, the Crude Birth Rate (number of births in relation to total population) is the indicator which provides us with the least information. Furthermore, this rate is very much influenced by population structure, by sex ratios and by levels of nuptiality. It is of little use for the purpose of researching the historical evolution of fertility or of comparing between different populations. Other measures have been used which allow us to achieve a higher degree of definition. This is the case, for example, with the General Fertility Rate or the General Marital Fertility Rate.

Ansley J. Coale (1965 and 1969) devised a set of indices (widely known as the Princeton Indices) for the European Fertility Project which have been - and continue to be- used in most historical studies on fertility. The fertility indices used in the European Fertility Project were designed taking two considerations into account. First, it was essential to bear in mind the effects of nuptiality on the total fertility of populations, as in most of Europe during the period in question procreation took place mainly, though not exclusively, within marriage. Second, the absence of detailed information (such as the age of women at marriage, the age of the mother at the birth of her children, etc.) in many countries for much of the period under study made it necessary to use measures that could be 
calculated using the simplest data available: the total number of births, the number of legitimate and illegitimate births, and the number of married and unmarried women in each age group.

Coale developed three measures or indices of fertility. These are memorably named: $I_{\mathrm{f}}$ (overall fertility), $I_{\mathrm{g}}$ (marital fertility) and $I_{\mathrm{h}}$ (illegitimate fertility). They express the level of fertility as a proportion of the fertility a population would have had if it had experienced the highest fertility pattern on record ${ }^{1}$. Coale also defined a fourth index which he called $I_{\mathrm{m}}$. This is not a measure of fertility but an index of marriage. It indicates the number of children which married women in a certain population would have in relation to the number of children all women in that population (married and non-married) would have if they were located at the same level of fertility as the married Hutterite women.

The index of marital fertility $\left(I_{\mathrm{g}}\right)$ is the proportion of the actual number of births to married women in relation to the number of births these same women would have had if they had been situated at the same level of age-specific fertility as married Hutterite women. Thus:

$$
I_{\mathrm{g}}=B_{\mathrm{L}} / \sum_{\mathrm{n}} m_{\mathrm{x}} F_{\mathrm{x}}
$$

where $B_{\mathrm{L}}$ is the annual number of legitimate births, ${ }_{\mathrm{n}} m_{\mathrm{x}}$ is the number of married women in each interval and ${ }_{\mathrm{n}} F_{\mathrm{x}}$ is the age-specific marital fertility rate of Hutterite women.

As Coale (1986: 156-162) has pointed out, the four Princeton Indices $\left(I_{\mathrm{f}}, I_{\mathrm{g}}, I_{\mathrm{h}}\right.$ and $I_{\mathrm{m}}$ ) are influenced by the age structure of the female population. This is a problem when trying to compare population indices with other age distributions. In fact, different populations subject to the same fertility schedule may have different values of a fertility index if the age distributions are different: the fertility indexes are not independent of the age distributions of the populations under observation.

Variations of these indices have been developed that incorporate direct standardization for the age distribution (Livi Bacci, 1971: 55; Knodel, 1974: 35; and Coale and Watkins, 1986). The modified version of the index of marital fertility is defined in the following manner:

$$
I_{\mathrm{g}}^{\prime}=\sum{ }_{\mathrm{n}} f_{\mathrm{x}} M_{\mathrm{x}} / \sum{ }_{\mathrm{n}} M_{\mathrm{x}} F_{\mathrm{x}}
$$

where ${ }_{n} f_{\mathrm{x}}$ is the fertility rate for married women in each interval in a specific population, ${ }_{\mathrm{n}} F_{\mathrm{x}}$ indicates the age-specific fertility rate of married Hutterite women, and ${ }_{\mathrm{n}} M_{\mathrm{x}}$ is the proportion of married women in each age interval in the 
Sánchez-Barricarte, $J$.

reproductive period of a standard population which, in our case, will be that of the number of married women indicated in the 1930 Spanish Census.

Whereas the original version of the $I_{\mathrm{g}}$ can be calculated using only the annual number of births, the modified version of $I_{\mathrm{g}}^{\prime}$ can only be calculated if we know the number of births classified according to the mother's age. It is very useful to have a summary measure of the marital fertility rate of a population in order to observe its historical development and draw comparisons between different regions and countries. Microstudies are increasingly available which make it possible to classify births according to the mother's age. Many of these studies still use the Princeton marital fertility index $\left(I_{\mathrm{g}}^{\prime}\right)$ as a summary measure. The main objective of this article is to draw attention to the drawbacks of using this index, and to propose a new index which we believe to be more precise than the summary measure.

What information does $I_{\mathrm{g}}$ provide? Practically the same as what is provided by the Total Marital Fertility Rate (TMFR) ${ }^{2}$ which is calculated on the basis of giving the same weight to all age-specific fertility rates. The TMFR (ages 20 to 49 ) indicates the number of children a woman would have if she were to marry at the age of 20 and survive throughout her child-bearing period being subjected to age-specific marital fertility rates $\left({ }_{n} f_{\mathrm{x}}\right)$. That is to say, when we compare the TMFR of two different populations, the mean age at marriage and the proportion of definite celibacy are not taken into account. In other words, both $I_{\mathrm{g}}{ }_{\mathrm{g}}$ and the TMFR measure the level of fertility of a population without regard to the mean age at which women marry or proportion never marrying. The degrees of correlation between the TMFR and $I_{\mathrm{g}}$ and $I_{\mathrm{g}}^{\prime}$ are very high $(0.990$ and 0.993 respectively $)^{3}$. In Figure 1 it can clearly be seen that the information provided by the TMFR (ages 20-49) and $I_{\mathrm{g}}$ is practically the same.

However, $I_{\mathrm{g}}{ }_{\mathrm{g}}$ and TMFR(20-49) do not seem to be good indicators of marital fertility, that is to say of the number of children each married couple has. Two populations having the same age-specific fertility rates $\left({ }_{n} f_{x}\right)$ but different female mean ages at marriage would produce the same levels of marital fertility by means of $I_{\mathrm{g}}$ or TMFR(20-49) although it would seem obvious that if in these populations the mean ages at marriage are 20 and 30 years respectively, the actual number of children per married couple would have to be substantially higher in the former case as compared to the latter. In other words, given that the age-specific marital fertility rates (ASMFR) are influenced by the mean age at marriage, it does not seem fully correct to compare ASMFR of a given population with those of the Hutterite women (which is what $I_{\mathrm{g}}{ }_{\mathrm{g}}$ does in effect) because we have no control on the mean age at marriage ${ }^{4}$.

The research carried out under the auspices of the European Fertility Project (Princeton University) suggests that the date of modern decline of fertility has to be established as that moment in which a country achieves an uninterrupted decline of $10 \%$ in its $I_{\mathrm{g}}$ values (Coale, 1986: 178-181). We have already pointed out that $I_{\mathrm{g}}$ and $I_{\mathrm{g}}$ give us the same information as does the Total Marital Fertility Rate. Two populations can have the same number of children per married couple 
but have different age-specific marital fertility rates (ASMFR) $)^{5}$ This would be so if, for example, in a given population women were to marry

Figure 1

Evolution of the Total Marital Fertility Rate (20-49 years) and I' in Rural Navarre

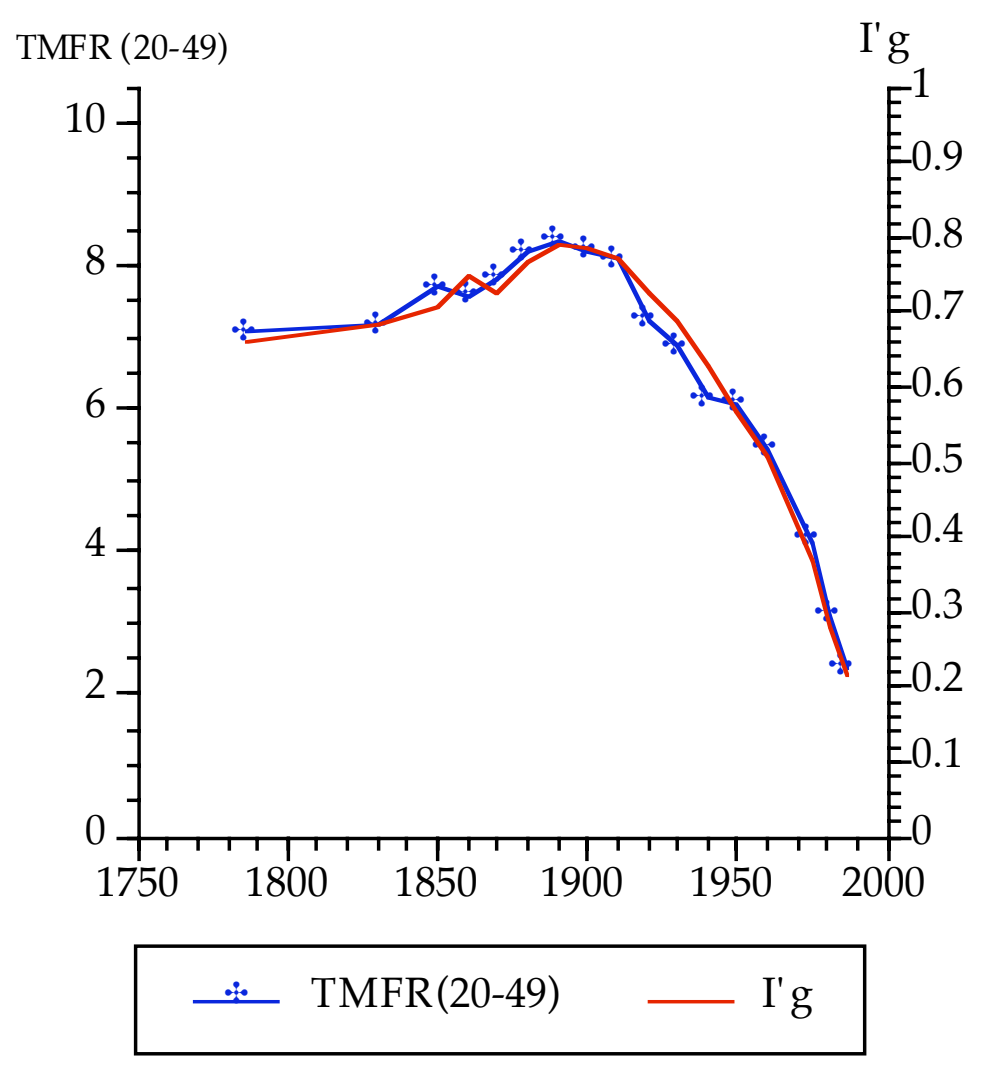

early and then be subject to low ASMFR, whereas in another population women were to marry late and then maintain high ASMFR. If in a given country women married younger and there were a decline in the age-specific marital fertility rates (which does not necessarily mean that the final number of offspring of married couples would be reduced), there would be a decline in $I_{\mathrm{g}}{ }_{\mathrm{g}}$ values. This shows that a higher Total Marital Fertility Rate or a higher $I_{\mathrm{g}}$ does not necessarily mean that married couples would be having more children and 
Sánchez-Barricarte, $J$.

therefore these indices can present certain problems when we try to study the historical evolution of fertility.

In a recent article, Guinnane, Okun and Trussell (1994) show that $I_{\mathrm{g}}$ cannot be used with complete reliability to determine the initial stages of the transition of fertility or to detect how rapidly birth control takes place. These authors consider that $I_{\mathrm{g}}$ is a measure that is not sensitive regarding the proportion of couples who practice birth control. Knodel (1988), in his study of 14 German villages, observed how marital fertility (measured by $I_{\mathrm{g}}^{\prime}$ ) changes very little due to the fact that the declining fertility of older women was offset by an increase in the fertility of younger women.

We know that those cohorts who marry later often have higher age-specific marital fertility rates than those who marry earlier. There are many studies that show that ASMFR are related to the age of marriage (we can see some examples in Tables 1 to 3 ).

The following simple exercise suffices to help us to understand why it is incorrect to use the TMFR as an indicator of the real fertility of a given population. We have already determined that the $\operatorname{TMFR}(20-49)$ is calculated by adding the age-specific marital fertility rates from 20 to 49 . In other words, we add what in Tables 1 and 3 appears as the ASMFR(total). Suppose now that in a given population all the women marry at age 20 and that the ASMFR they are subject to are the ones indicated in Table 4. In this theoretical population, if the women were to survive till the end of their fertility period they would have an average of 8.5 children.

Now suppose that only $10 \%$ of the women marry at age 20 and that the remaining $90 \%$ do so at age 30 and that the ASMFR according to marrying age are the ones detailed in Table 5. Notice that we are using the same ASMFR as Knodel (1988) calculated for Germany which appear in Table 2. If all women were to survive till the end of their reproductive period, then those who married at 20 would have had an average of 8.5 children, while those who married at 30 would have had an average of 4.9 children (which is logical since they married later). In other words, the average number of children born to all the married women would be $(8.5 * 0.1)+(4.9 * 0.9)=5.3$ children. The delay in the marrying age in $90 \%$ of the women would produce a strong decline in the total marital fertility. However, in Table 5 we can see how the Total Marital Fertility Rate (20-49) for that same population increases from 8.5 to 9.4. This happens because of the way in which the TMFR is calculated (this rate is a synthetic index, that is to say that it is calculated by using age-specific marital fertility rates which pertain to different marriage cohorts).

In other words, a delay in the marrying age in some of the women produces an increase in the TMFR. This should caution us against using this index as an indicator of the total marital fertility of a population. In the example we have previously mentioned, not only did the TMFR(20-49) not indicate that the 


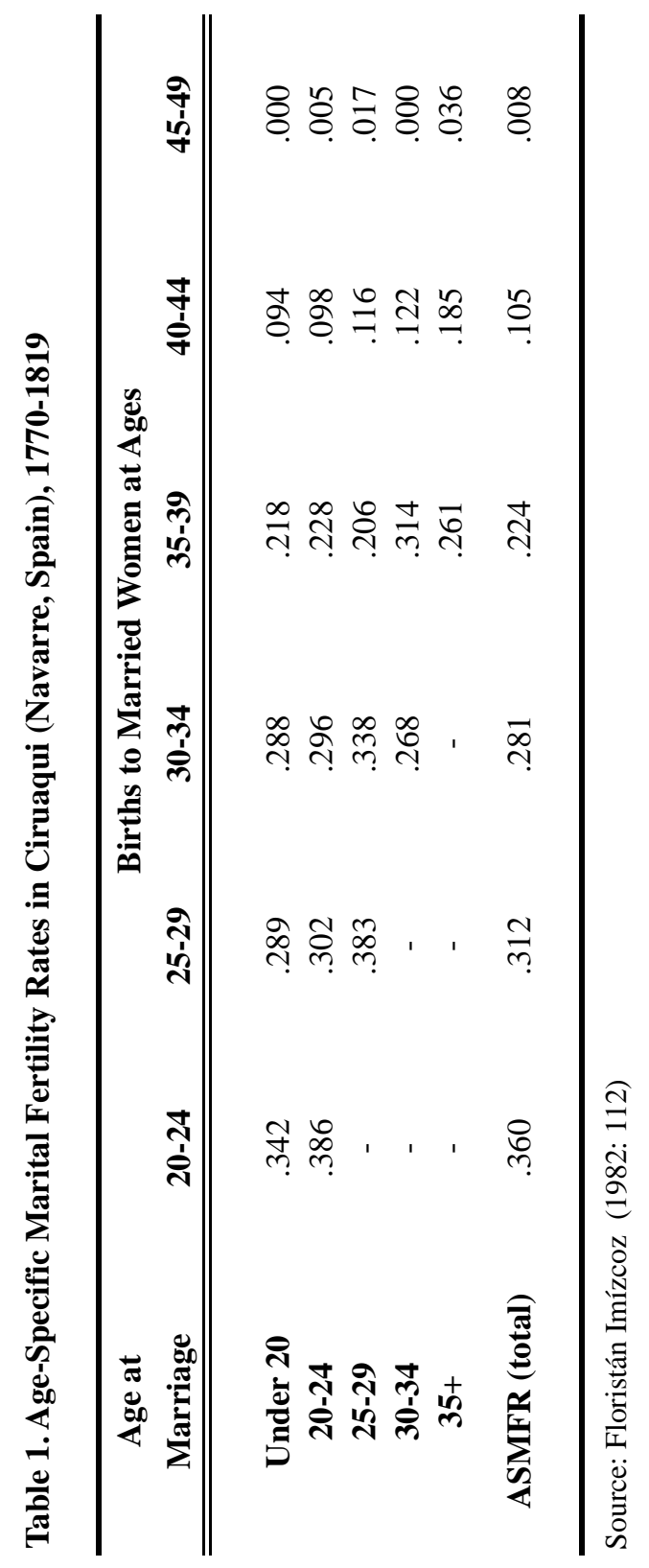


Sánchez-Barricarte, J.

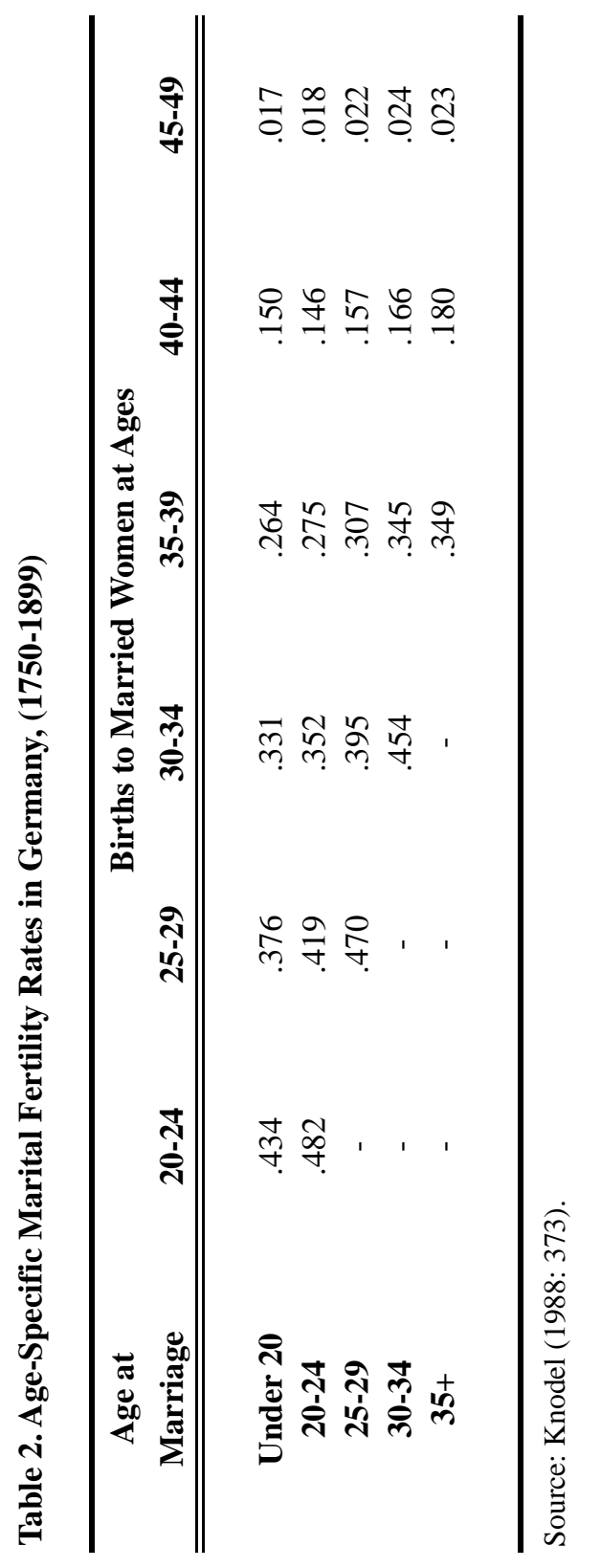


A New Proposal for Measuring Marital Fertility in Historical Populations

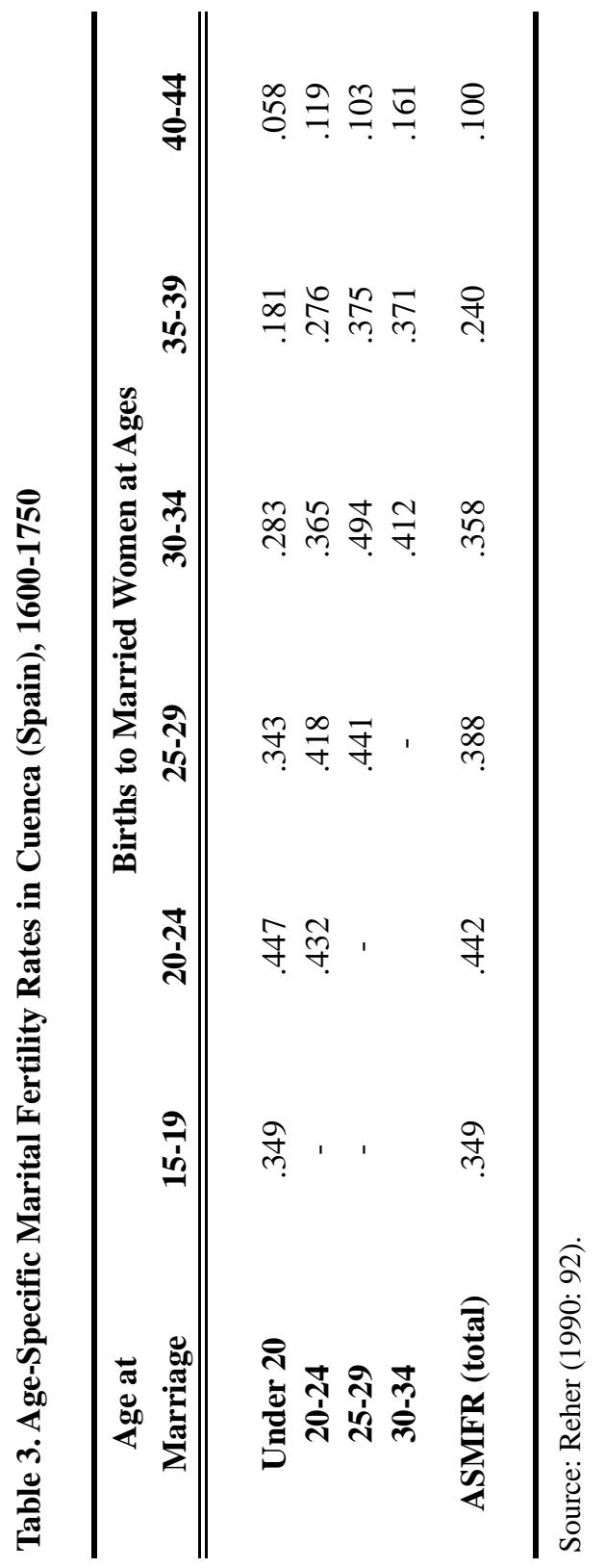


Sánchez-Barricarte, J.

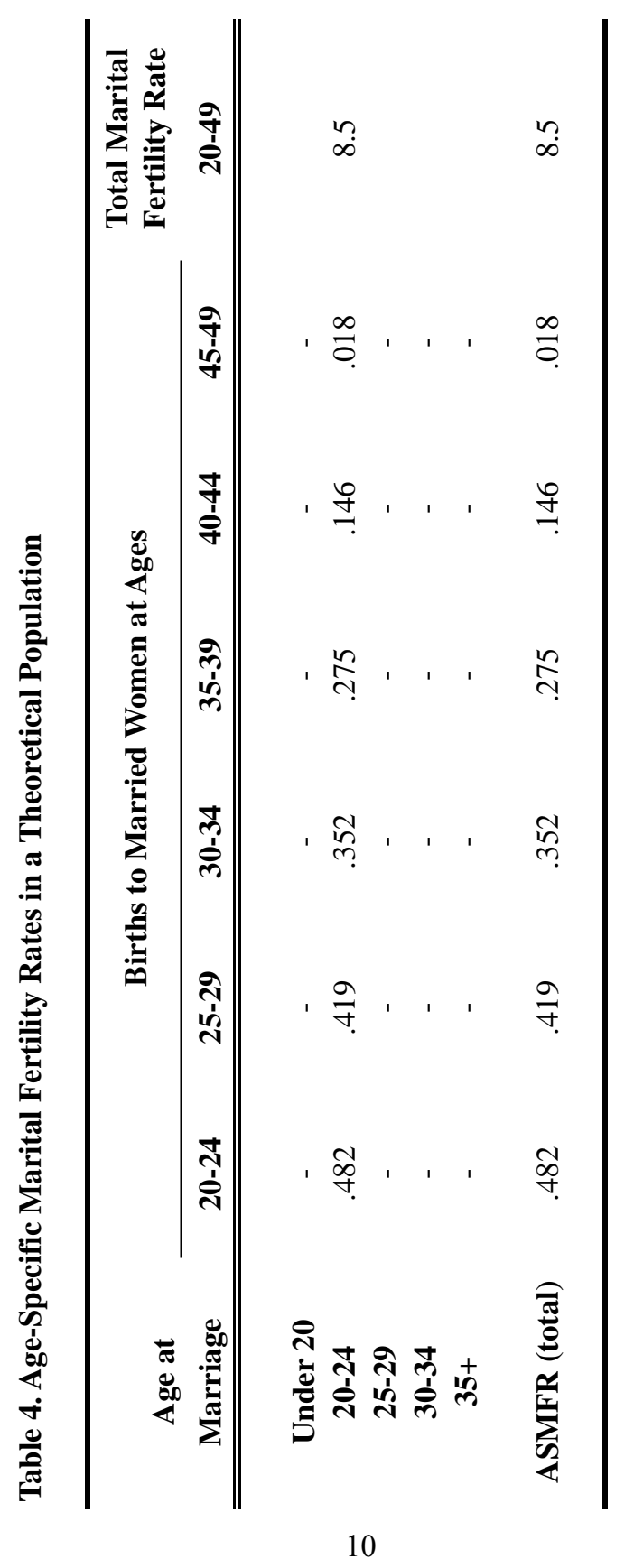




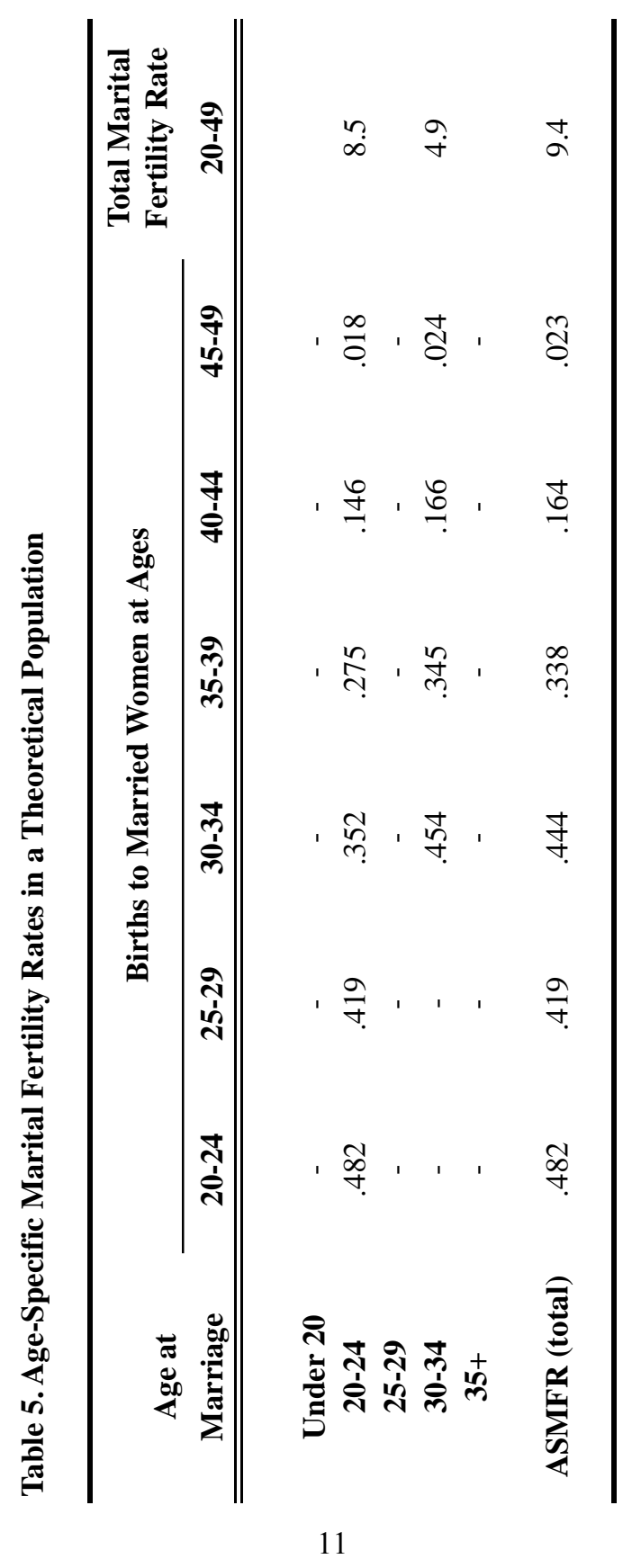


Sánchez-Barricarte, J.

marital fertility of that given population had declined but, on the contrary, it told us that it had increased (which is not true).

We have confirmed that the $I_{\mathrm{g}}$ index behaves in the same way as the TMFR(2049) and that both indices have high levels of correlation; therefore we must exercise great caution in interpreting both when using then as summary measures in the study of the level of marital fertility in a given population.

ASMFR are related to the age of marriage and therefore when we calculate a summary measure of marital fertility (that is, directly related to the number of children that a married couple actually has), this has to be done in such a manner that both the ASMFR and the mean age at marriage are taken into account.

For all these reasons we see that $I_{\mathrm{g}}$ or the TMFR are equivocal indices of marital fertility since they do not measure precise average decline per married couple and therefore the real number of offspring an average family has at a particular historical moment. It is this average family size which we are interested in measuring - along with its changes in time - because it can describe the real situation of families better than $I_{\mathrm{g}}^{\prime}$ or the TMFR.

We have developed a new index which takes into account the ideas developed above. We call this new index the Navarre Index and we refer to it with the initials NI. This index has been developed in a research project conducted in the Spanish province of Navarre ${ }^{6}$. The $N I$ is calculated in the following manner:

A. Net Index of Marital Reproduction

$$
\begin{gathered}
N I_{\mathrm{mr}}=\sum_{\mathrm{x}}=\mathrm{k} \\
{ }_{\mathrm{n}}
\end{gathered}
$$

where ${ }_{n} f_{x}$ is the fertility rate of married women in each age-group in a specific population, ${ }_{n} L_{\mathrm{x}}$ is the number of person-years lived by married women and $\mathrm{k}$ is the mean age at first marriage (MAFM) ${ }^{7}$. What this index indicates is the average number of legitimate children a woman is expected to have (regardless of whether she survives until the end of her reproductive period or not) if she marries at the mean age at first marriage of the given population in which she finds herself. This index, in a word, is a period measure of the family size or of the hypothetical number of children per woman who married at a given MAFM. As opposed to the Princeton Indices, the $N I_{\mathrm{mr}}$ takes into account the probability of death among women of reproductive age. We consider this to be important when establishing the fertility level in historical studies. Furthermore, this index is not influenced by the age structure of the female population.

It is important to note that the $N I_{\mathrm{mr}}$ is still a synthetic index, that is to say that it is calculated by using ${ }_{n} f_{x}$ which pertain to different cohorts. We assume that the cohorts of women who marry at a given moment will be subject to the age- 
specific marital fertility rates of the preceding cohorts, a fact that can distort reality at moments of important changes in fertility ${ }^{8}$.

The Net Index of Marital Reproduction $\left(N I_{\mathrm{mr}}\right)$ is not a pure index of marital fertility since it takes into account the probability of death among women of reproductive age, as well as nuptiality. It would be quite easy to put together a pure index of fertility:

$$
\begin{array}{rl}
\mathrm{NI}^{\wedge}{ }_{m r}=\sum_{\mathrm{X}}=\mathrm{k} & 49 \\
\mathrm{f}_{x}(\text { marital })
\end{array}
$$

This index indicates the average number of legitimate children per woman who married at the age of $\mathrm{k}$ and survived until the end of her reproductive period. $N I_{\mathrm{mr}}$ are approximate values of the average number of legitimate children per married woman. These indices are calculated by taking into account the mean age at which women marry, age-specific marital fertility rates and the probability of survival of married women from the mean age of marriage up to the end of their reproductive period. In fact there are other factors which are brought to bear on the average number of children and which we have not taken into account, such as the probability of survival on the part of husbands, the risk of divorce and the probability of subsequent marriages on the part of widowed women. The probability of a woman becoming widowed has decreased due to the increase in male life expectancy. This could account for the fact that figures on the average number of children per married woman $\left(N I_{\mathrm{mr}}\right)$ in the nineteenth century and the beginning of the twentieth century were somewhat inflated. In those years, the probability of widowhood among women prior to the termination of the reproductive period was higher, and so the chance of having more children was diminished. Nonetheless, the fact that many widowed women remarried makes our approximation of the values of $N I_{\mathrm{mr}}$ come closer to reality.

The possibility of remarriage depended, in essence, on the age at which women become widows. The great majority of women widowed before the age of $30 \mathrm{did}$ in fact remarry. According to Floristán Imízcoz (1982: 106), 58\% of widows under the age of 40 in the Navarrese municipality of Cirauqui remarried in the period between 1640 and 1789. The average duration of actual widowhood prior to remarriage was approximately two years.

\section{How Well Does the Navarre Index $\left(n i_{\mathrm{mr}}\right)$ Work?}

We have done several tests to evaluate how well this index fits reality. In the 1940 Spanish Census a set of questions were asked on female fertility. Women were asked about the number of living children they had, the number of children who had died and the number who were stillborn ${ }^{9}$, and the number of years they had been married. With this information we drew up Table 6 in which we can 
Sánchez-Barricarte, J.

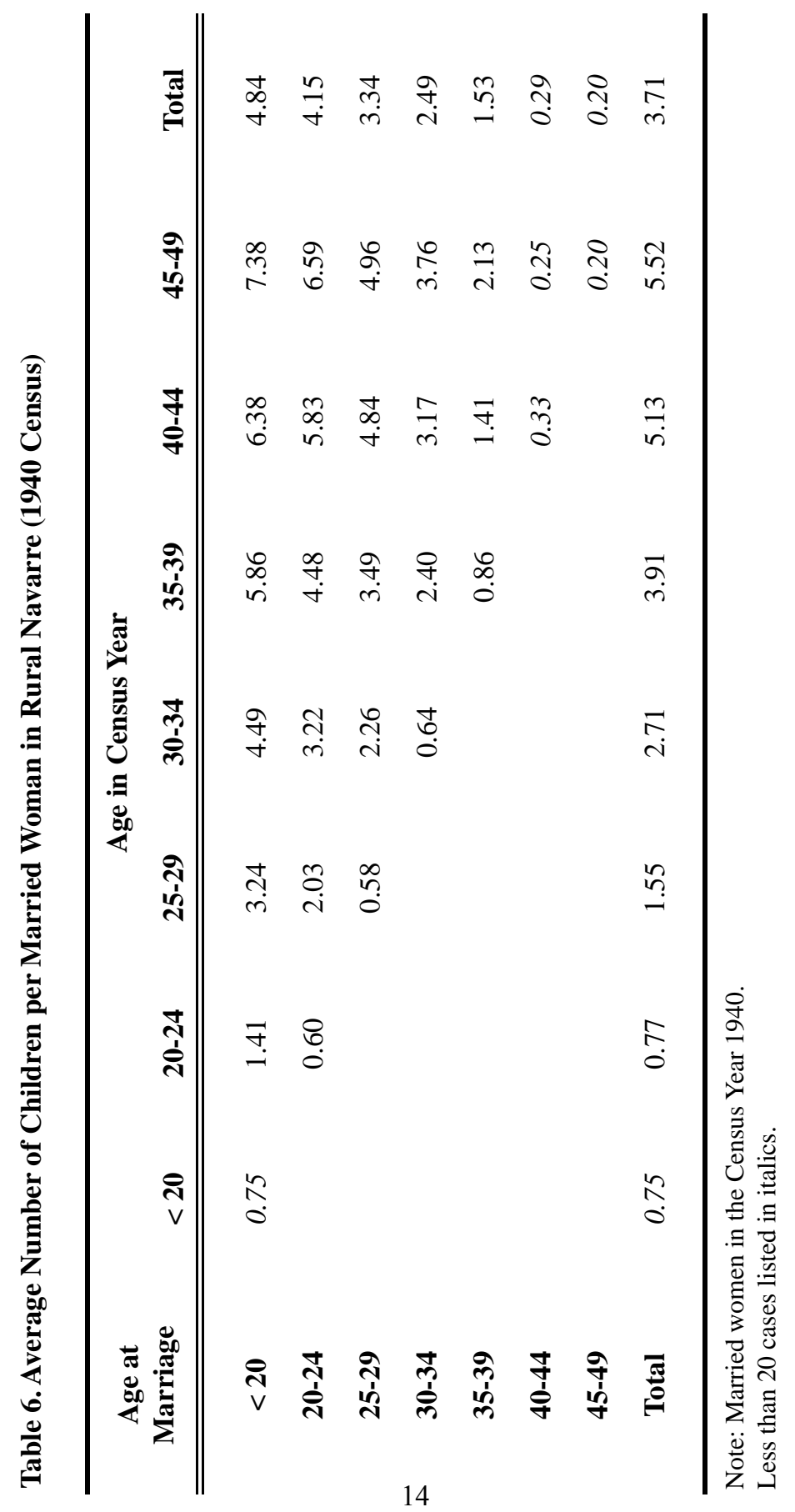


appreciate how, indeed, the number of children per women of the same agegroup is higher among those who married at younger ages. Thus, married women who were aged 45-49 in 1940 and had married before the age of twenty had an average of 7.4 children. Women from the same age group (45-49) who had married between the ages of 25 and 29 had an average of 5.0 children. The same trend is observed in all the age groups: the younger the women married, the greater the total number of children they had.

In general, the mean age at marriage for the women of a population should have a negative relation to whatever index of marital fertility we may be using. We correlated the mean age at first marriage for women in some thirty municipalities of the province of Navarre with the values of the $N I_{\mathrm{mr}}$ and obtained the results observed in Table 7 . As one can see, for practically every year from 1850 to 1991 this correlation was negative as expected. Nevertheless, when we correlate the mean age at first marriage for women from these same towns to the $I_{\mathrm{g}}^{\prime}$ values, the correlation becomes positive (in some cases, with statistical significance). This proves that the $N I_{\mathrm{mr}}$ is a better predictor of marital fertility than the $I_{\mathrm{g}}$.

Knodel (1988: 363) finds a positive association of 0.67 between total marital fertility measured with $I_{\mathrm{g}}^{\prime}$ and the age of marriage in his study of German villages. Nonetheless, this same author verified that the age of marriage correlates negatively $(-0.57)$ with the number of children per married woman.

Using information from the 1940 Spanish Census, we chose, in 24 municipalities of Navarre, those women who in the year 1940 were aged 40 to 49 years old, had been married more than ten years and were still married. We correlated the average number of children per woman in each municipality, calculated with this information, along with the average of $I_{\mathrm{g}}^{\prime}$ in 1930 and 1940 and the average of the $N I_{\mathrm{mr}}$ in the same years. The results were the following

$I_{\mathrm{g}}(1930-1940)$ and average number of children per woman aged 40-49 in 1940, $\mathrm{R}=0.699(\mathrm{~F}-\mathrm{Test}=19.9 ; \mathrm{p}=0.0002)$

$N I_{\mathrm{mr}}$ (1930-1940) and average number of children per woman aged 40-49 in 1940, $\mathrm{R}=0.770(\mathrm{~F}-\mathrm{Test}=29.6 ; \mathrm{p}=0.0001)$

The correlation is higher with the $N I_{\mathrm{mr}}$ than with $I_{\mathrm{g}}^{\prime}$, that is the Net Index of Marital Reproduction seems to predict better the levels of fertility of the different municipalities. The correlation is quite high if we take into account the fact that the average number of children per woman aged 40-49 of the 1940 Census are those begotten by one and the same cohort throughout its reproductive period, whereas, as we have already stated, the $N I_{\mathrm{mr}}$ are calculated on the basis of the age-specific fertility rates of different cohorts. Furthermore, the period between 1920 and 1940 was a time of continued decline in marital fertility and therefore the presupposition we work with when calculating the $N I_{\mathrm{mr}}$ 
Sánchez-Barricarte, J.

Table 7

Correlation Levels ( $R$ ) between Mean Age at First Marriage in Rural Navarre and NImr and I'g (Municipal Level)

\begin{tabular}{lll}
\hline Year & NImr & I'g \\
\hline \hline $\mathbf{1 8 5 0}$ & $-.46 *$ & .32 \\
$\mathbf{1 8 6 0}$ & $-.55 *$ & .22 \\
$\mathbf{1 8 7 0}$ & $-.65 *$ & $.70 * *$ \\
$\mathbf{1 8 8 0}$ & $-.48 *$ & .34 \\
$\mathbf{1 8 9 0}$ & -.20 & $.47 *$ \\
$\mathbf{1 9 0 0}$ & $-.51 * *$ & .17 \\
$\mathbf{1 9 1 0}$ & $-.37 *$ & .25 \\
$\mathbf{1 9 2 0}$ & $-.52 * *$ & .20 \\
$\mathbf{1 9 3 0}$ & $-.40 *$ & .05 \\
$\mathbf{1 9 4 0}$ & -.06 & .28 \\
$\mathbf{1 9 5 0}$ & $.40 *$ & $.51 * *$ \\
$\mathbf{1 9 6 0}$ & .10 & $.46 *$ \\
$\mathbf{1 9 7 5}$ & -.33 & .02 \\
$\mathbf{1 9 8 6}$ & $-.54 * *$ & .16 \\
\hline
\end{tabular}

** Significant at the .001 level.

* Significant at the .01 level. 
- in the sense that the cohorts that marry are subject to the age-specific fertility rates of preceding cohorts - is not altogether appropriate.

We performed a simulation in a hypothetical population to test the behavior of the different indices under different circumstances (high or low fertility, high or low mortality, changes in the age at which women marry, changes in the fertility rates, and so on).

Our first finding in this simulation was that the correlation between the TMFR(20-49) and the $I_{\mathrm{g}}{ }_{\mathrm{g}}$ index, both in populations with natural fertility and in those with a high degree of birth control, is very high $\left(R^{2}=0.99\right)$ (see results in Appendix I).

Figures 2 and 3 show how the adjustment between $N I_{\mathrm{mr}}$ and family size is very high (Appendix I specifies the data on marital fertility, mortality and age of women at marriage which we used to perform the simulation).

Family size indicates the mean number of children a woman has at the end of her reproductive period. This is subject to the specific rates of marital fertility and the mortality rates specified in Appendix I.

Figures 2 and 3 demonstrate how, in both populations with natural and controlled fertility ${ }^{10}$, when the age of marriage is higher, the mean number of children per married woman (family size) falls. This trend is reflected perfectly in the $N I_{\mathrm{mr}}$.

What happens to the $I_{\mathrm{g}}^{\prime}$ values? Figure 4 shows how a population which maintains constant marital fertility rates but in which the age of women at marriage is increasing sees a rise in $I_{\mathrm{g}}{ }_{\mathrm{g}}$ values. This is surprising, since Figures 2 and 3 show that what really happens is that each woman, on average, has fewer children at the end of her reproductive period.

What happens when the age of women at marriage is constant within a population, but the situation changes from one of natural to one of controlled fertility? The results are set out in Figure 5. This shows how the three indices $\left(N I_{\mathrm{mr}}\right.$, family size and $\left.I_{\mathrm{g}}^{\prime}\right)$ fall. However, whereas the $N I_{\mathrm{mr}}$ index greatly resembles what has really happened (family size), the drop in $I_{\mathrm{g}}^{\prime}$ is much smaller.

On the basis of all the above discussions, we can conclude that the $N I_{\mathrm{mr}}$ index is highly sensitive to the variations in the mean number of children per married woman in any situation (high or low fertility, high or low mortality, changes in age of marriage). By contrast, the $I_{\mathrm{g}}$ index is only able to detect increases or decreases in the marital fertility levels during periods in which the age of women at marriage remains constant. It does, however, reflect all the variations which may occur in fertility rates. 
Sánchez-Barricarte, $J$.

Figure 2

Evolution of $N I_{\mathrm{mr}}$ and family size for scenarios 1 and 3

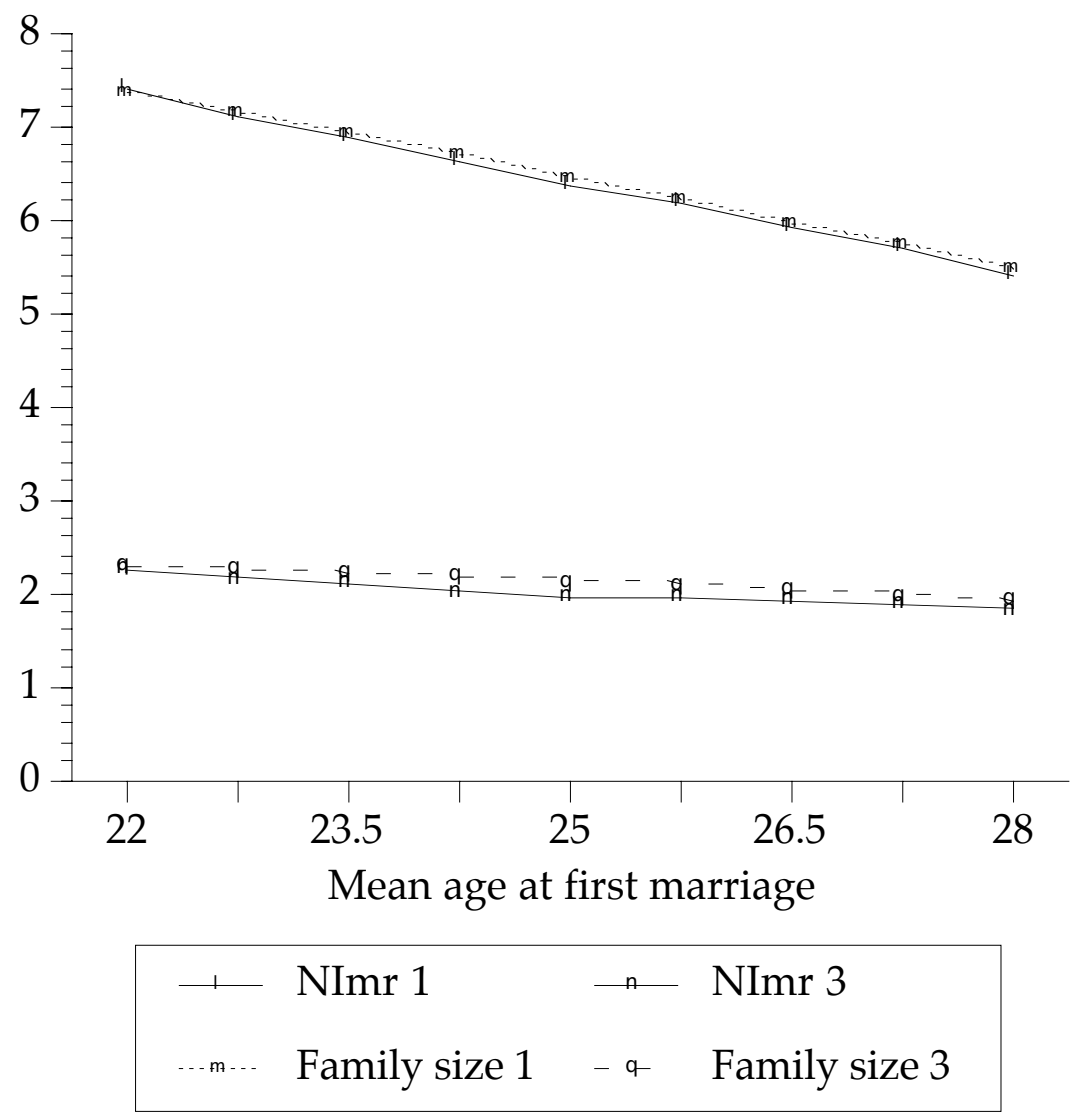

Note:

$N I_{\mathrm{mr}} 1$ and family size 1: Natural fertility and low mortality.

$N I_{\text {mr }} 3$ and family size 3: Controlled fertility and low mortality. 
A New Proposal for Measuring Marital Fertility in Historical Populations

Figure 3

Evolution of $N I_{\mathrm{mr}}$ and family size for scenarios 2 and 4

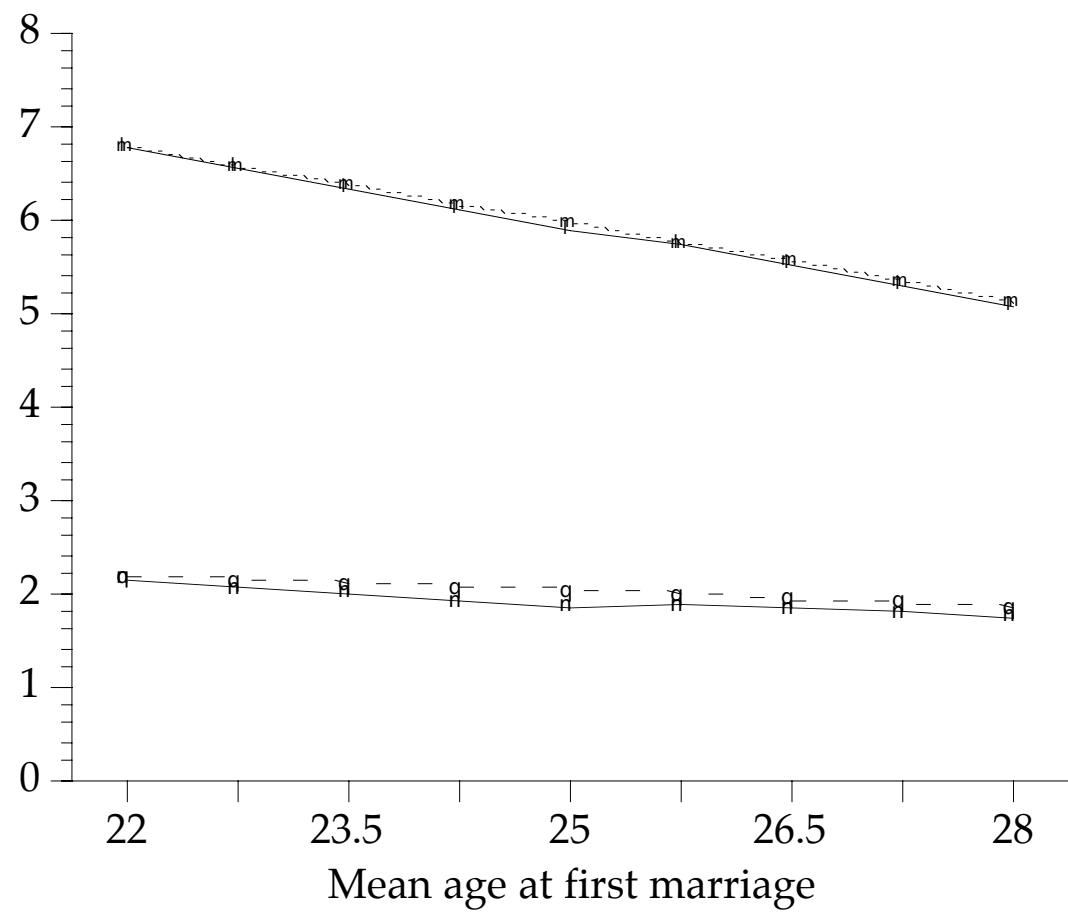

\section{$\longrightarrow$ NImr $2 \quad n \quad$ NImr 4 \\ …m... Family size $2 \quad-q \quad$ Family size 4}

Note:

$N I_{\mathrm{mr}} 2$ and family size 2: Natural fertility and high mortality.

$N I_{\mathrm{mr}} 4$ and family size 4: Controlled fertility and high mortality. 
Sánchez-Barricarte, J.

Figure 4

Evolution of $N I_{\mathrm{mr}}$ and $I_{\mathrm{g}}$.

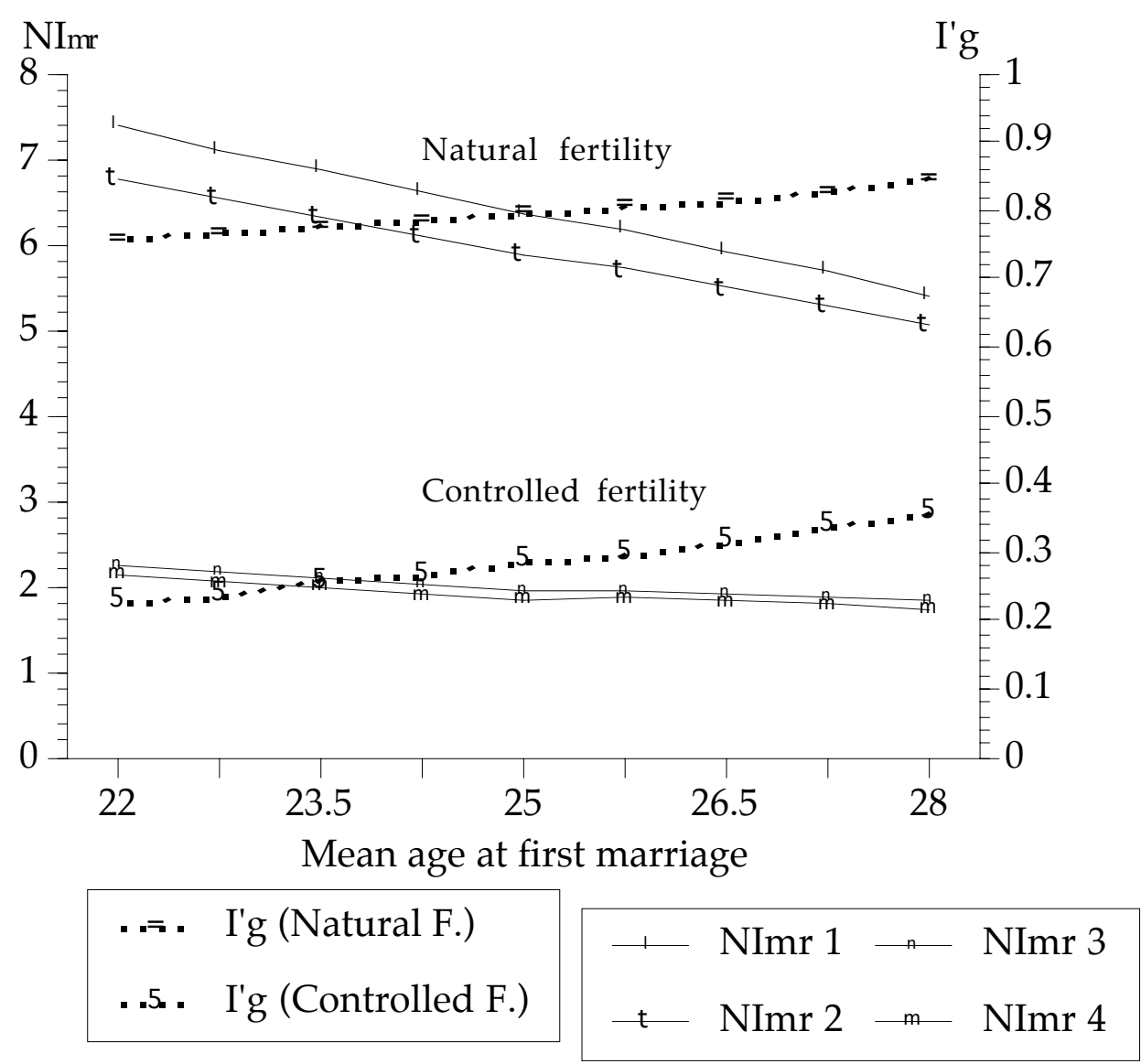


Figure 5

Evolution of $N I_{\mathrm{mr}}$, family size and $I_{\mathrm{g}}$.

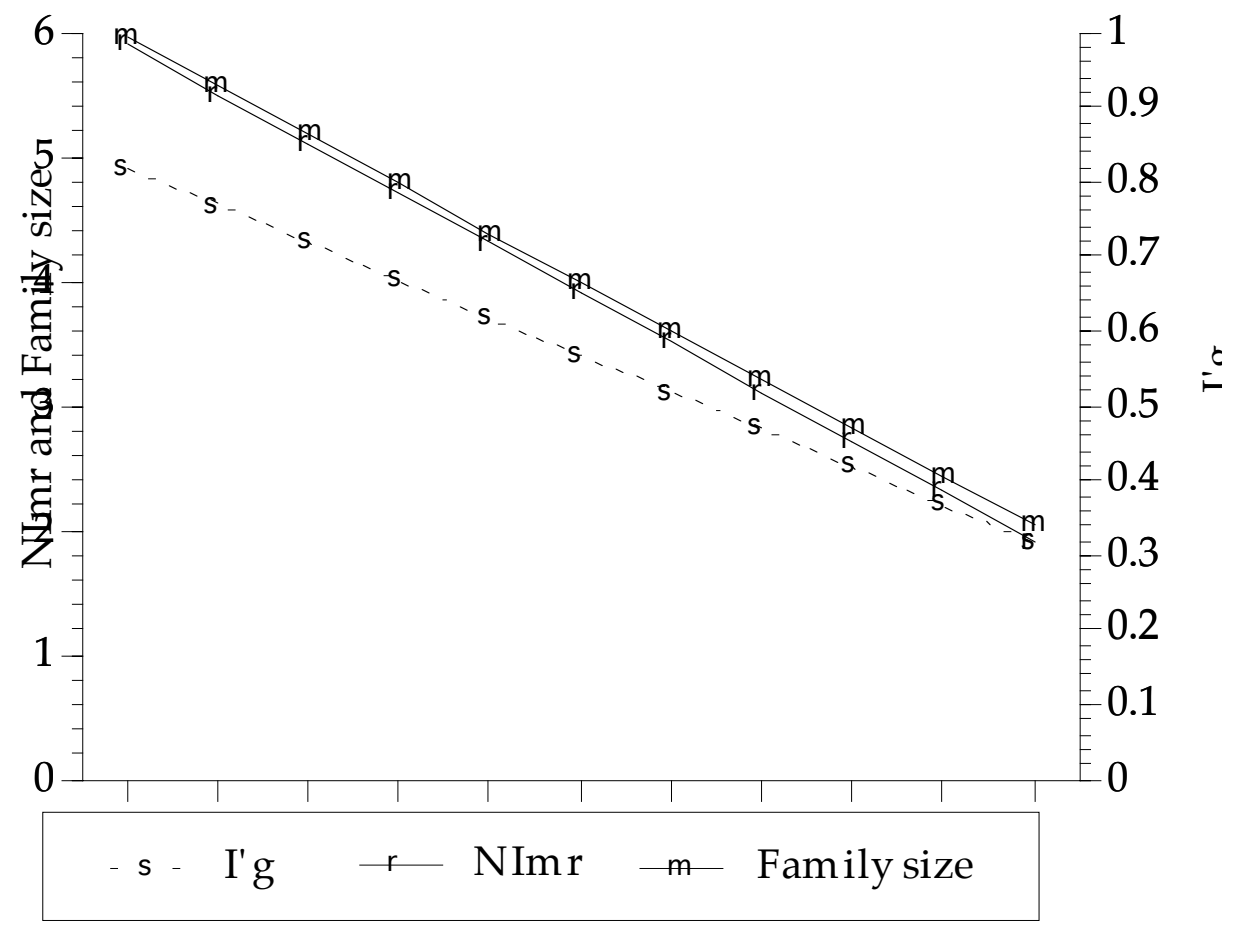

Note:

Mean age at marriage: 26.5

Low mortality. 
Sánchez-Barricarte, $J$.

\section{Comparative Analysis of the Princeton Index $\left(i_{\mathrm{g}}^{\prime}\right)$ and the Navarre Index $\left(n i_{\mathrm{mr}}\right)$}

In Figure 6 we can observe notable differences in the evolution of the $N I_{\mathrm{mr}}, I_{\mathrm{g}}$, and $I_{\mathrm{g}}$, especially between 1900 and 1960, when an important rise in the mean age at first marriage (MAFM) took place. For Navarre the MAFM of women in 1900 was 24.2, whereas in 1960 it was 26.6.

If we were to measure levels of marital fertility in agreement with the $I_{\mathrm{g}}$ index, we would have to say that marital fertility has always been higher in the Pyrenean Valleys than in the Ribera of Estella (see Figure 7). Nonetheless, if we were to observe what the $N I_{\mathrm{mr}}$ shows us (Figure 8) for the same geographical areas and in the same time frame, we would find quite a different picture. Until 1900 marital fertility in the Ribera of Estella was almost always higher than that of the Pyrenean Valleys. From 1900 to 1940 these levels balanced out and it is only from 1940 onwards the levels of the Pyrenean Valleys surpass those of the Ribera of Estella. These discrepancies between $I^{\prime}$ g and the $N I_{\mathrm{mr}}$ are due to the fact that the former do not take into account variations in the MAFM, whereas the latter do.

In Table 8 we can observe the differences in the year in which a $10 \%$ decline in marital fertility took place as a function of the index we are using. In the concrete case of the Ribera of Tudela the difference is as much as 15 years.

We can conclude briefly by emphasizing the importance of taking the mean age at first marriage into account when calculating a summary measure of marital fertility. Since the ASMFR are closely related to age at marriage, the summary measures of marital fertility which do not take account of the mean age at marriage, such as the $I_{\mathrm{g}}$ or the TMFR, may even distort real developments in the fertility rate among married couples within a population. In some cases (for example, when there is an important delay in female mean age at marriage) can even indicate an increase in marital fertility when in reality it is decreasing 
A New Proposal for Measuring Marital Fertility in Historical Populations

Figure 6

Evolution of $N I_{\mathrm{mr}}, I_{\mathrm{g}}$ and $I_{\mathrm{g}}$ in Rural Navarre

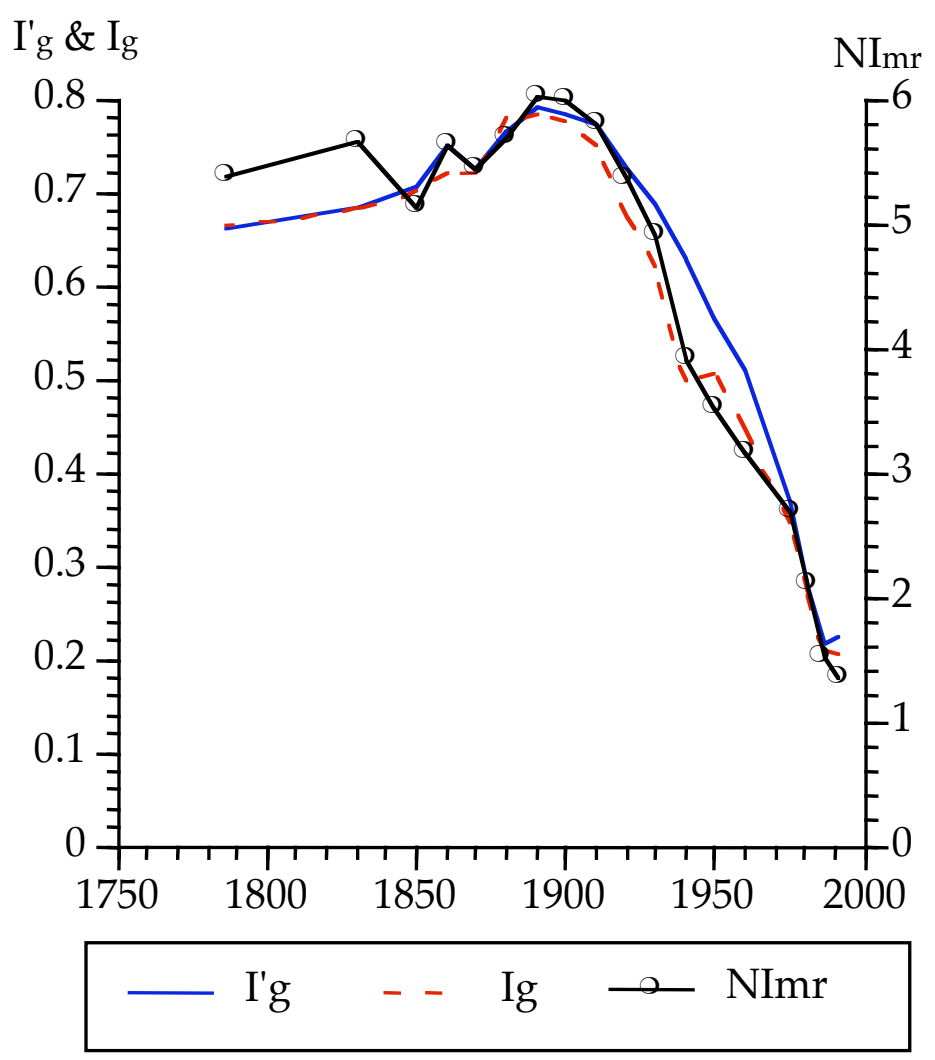


Sánchez-Barricarte, J.

Figure 7

Evolution of $I_{\mathrm{g}}$ values

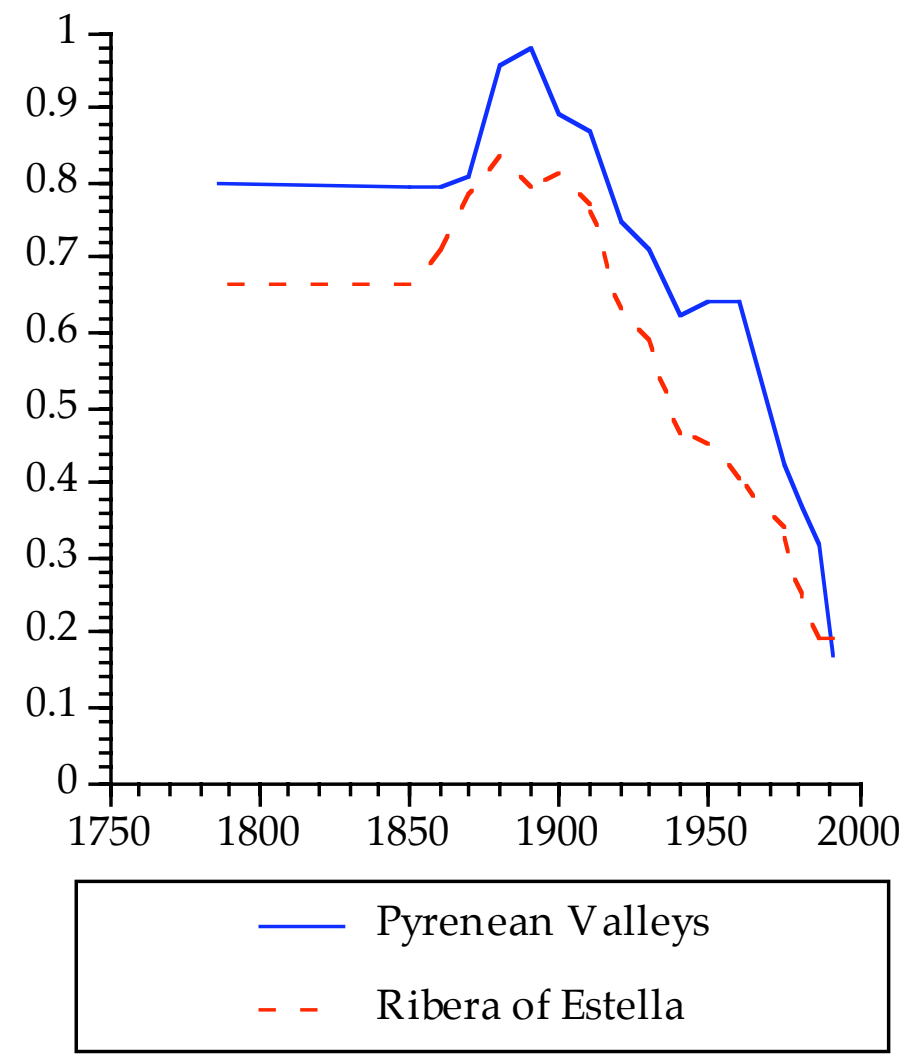


A New Proposal for Measuring Marital Fertility in Historical Populations

Figure 8

Evolution of $N I_{\mathrm{mr}}$ values

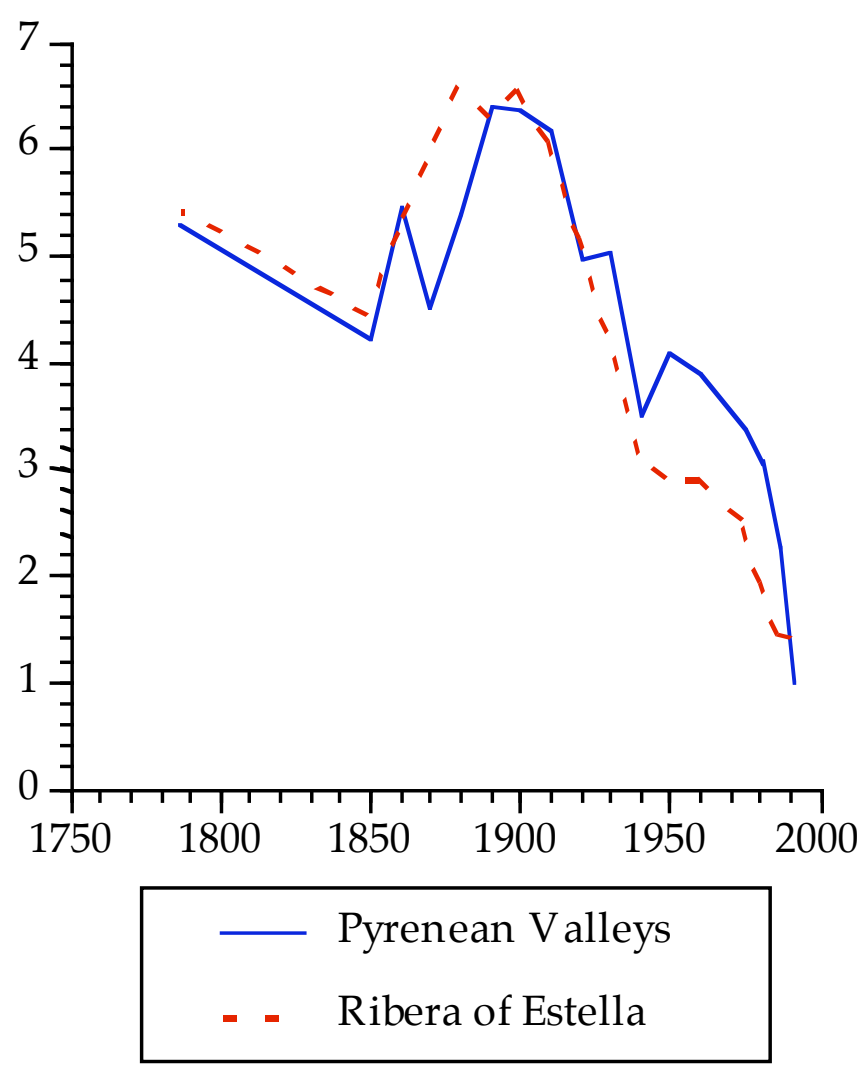


Sánchez-Barricarte, J.

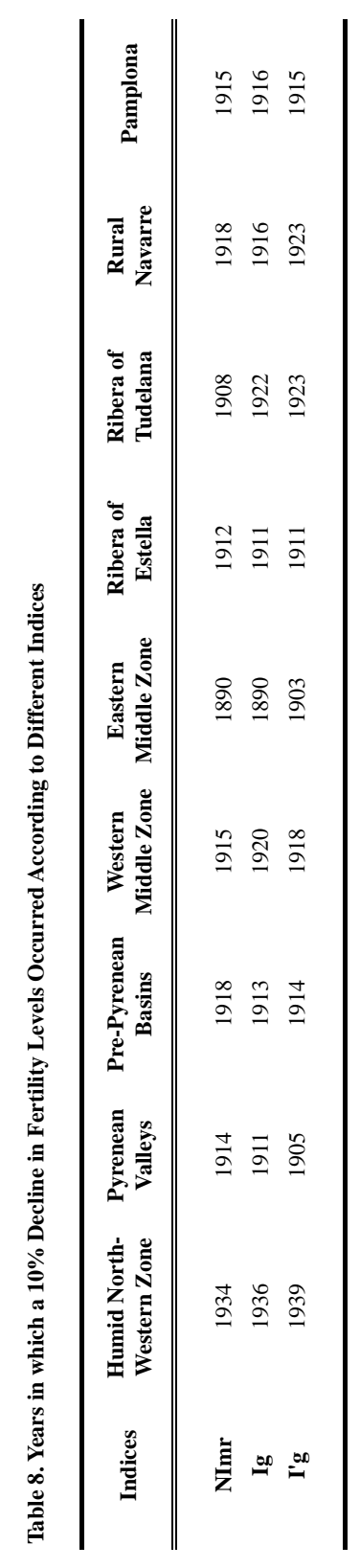


A New Proposal for Measuring Marital Fertility in Historical Populations

\section{End Notes:}

1. The group of people with the highest reliably recorded fertility are the Hutterites. The Hutterites are a Protestant religious sect (Anabaptists) founded in the sixteenth century. To avoid persecution for their religious beliefs they emigrated from Western Europe to Russia in the eighteenth century and finally to the North-Western zone of the United States and the south-central part of Canada in the nineteenth century. Fertility is high among the Hutterites because the sect prohibits contraception and abortion, while breast-feeding is carried out by mothers for just a few months after birth.

2. The Total Marital Fertility Rate (TMFR) $=\sum{ }_{n} f_{x} * n$, whereby ${ }_{n} f_{x}$ is the agespecific fertility rate of married women in each age group.

3. Using data from Reher (1988: 119) for the Spanish province of Cuenca (1850-1970), we found a correlation of $\mathrm{R}=0.994$ between TMFR(20-49) and $I_{\mathrm{g}}$.

4. It is very important not to forget that we are referring to age-specific fertility rates of a period, that is pertaining to different cohorts.

5. It could also happen that two populations have the same ASMFR $\left({ }_{n} f_{\mathrm{x}}\right)$ and yet a different number of children per married couple.

6. Located in the north of Spain, it spreads from the Ebro River Valley in the south to the western reaches of the Pyrenees in the north. It has a surface area of $10,421 \mathrm{~km}^{2}$. We proceeded to choose the municipalities as objects of this study in the following manner. On the basis of the division of Navarre carried out by Professor Floristán Samanes (1986) in the Gran Atlas de Navarra, we chose various municipalities from each of the geographical comarcas or local districts established. Professor Floristán divides Navarre into seven homogeneous geographical comarcas; these are the so-called "Comarcas Floristán" and the villages chosen for our sample are the following:

a) Humid North-western Zone: Echarri-Aranaz, Huarte-Araquil, Larráun, Leiza, Lesaca and Vera de Bidasoa.

b) Pyrenean Valleys: Burguete, Erro, Garralda, Orbaiceta, Burgui, Escároz and Roncal.

c) Pre-Pyrenean Basins: Aoiz, Lumbier, Monreal and Urroz.

d) Western Middle Zone: Abárzuza, Améscoa, Bargota, Cirauqui and Los Arcos. 
Sánchez-Barricarte, J.

e) Eastern Middle Zone: Puente la Reina, Cáseda, Olite and Sangüesa.

f) Ribera of Estella: Azagra, Falces, Lerín and Peralta.

g) Ribera of Tudela: Cabanillas, Cascante, Corella, Murchante, Valtierra and Villafranca.

7. The calculation of $N I_{\mathrm{mr}}$ is more precise if we have ${ }_{1} f_{\mathrm{x}}$ and ${ }_{1} L_{\mathrm{x}}$ at our disposal. However, the difference between the $N I_{\mathrm{mr}}$ calculated with the fertility rates for one-year $\left(f_{\mathrm{x}}\right)$ and five-year age-groups $\left.{ }_{5} f_{\mathrm{x}}\right)$ is very small (less than 1\%).

8. Given that the age-specific marital fertility rates are related to the age of marriage, the fact that $N I_{\mathrm{mr}}$ is a synthetic index makes it more difficult to come close to reality since in order to calculate this index we combine the mean age at marriage of a given year with the age-specific marital fertility rates of different cohorts. The ideal thing would be to combine the mean age at marriage of a specific cohort with the ASMFR which that same cohort would be experiencing throughout the reproductive period (cohort analysis).

9. Normally, stillborn children are not accounted for in calculations of birth rates; by including here data on children that were born dead, the fertility rates we have calculated are slightly higher than they were in point of fact. In spite of this slight distortion we believe that it was worthwhile to use these statistics.

10. The concept of natural fertility was developed by Louis Henry to refer to fertility in the absence of voluntary birth control. According to Henry, in a regime of natural fertility a couple's behavior is not modified as a function of the number of children which that couple already has (Henry, 1961). What distinguishes natural fertility from controlled fertility is not so much their levels but rather the behavior of couples in function of the number of children they already have. The level of natural fertility can oscillate a great deal because the factors determining it are variable (bio-physical factors: duration of the fertile period, sterility, capacity for child-bearing, intrauterine death; and behavioral factors: frequency of sexual relations, sexual taboos, duration of breast-feeding, etc.). 
A New Proposal for Measuring Marital Fertility in Historical Populations

\section{References:}

Coale, A. J. 1969. "The Decline of Fertility in Europe from the French Revolution to World War II" in Fertility and Family Planning, edited by S. J. Behrman, Leslie Corsa and Ronald Freedman. Ann Arbor, Michigan: University of Michigan Press.

Coale, A. J. 1965. "Factors associated with the development of low fertility: an historic summary," in United Nations World Population Conference, Belgrade, 1965, New York. Pp. 205-207.

Coale, A. J. and S. C. Watkins. 1986. The Decline of Fertility in Europe, Princeton: Princeton University Press.

Floristán Samanes, A. 1986. Gran Atlas de Navarra. Tomo I: Geografía. Pamplona: Caja de Ahorros de Navarra.

Floristán Imízcoz, A. 1982. La Merindad de Estella en la Edad Moderna: los hombres y la tierra. Institución Príncipe de Viana.

Floristán Samanes, A. 1951. La Ribera Tudelana de Navarra. Zaragoza: Diputación Foral de Navarra-C.S.I.C.

Guinnane, T. W., B. S. Okun, and J. Trussell. 1994. "What do we know about the timing of fertility transitions in Europe?" Demography, 31: 1-20.

Henry, L. (1961) "Some data on natural fertility," Eugenics Quarterly, 8(2): 81-91.

Knodel, J. 1988. Demographic Behavior in the Past: A Study of Fourteen German Village Populations in the Eighteenth and Nineteenth Centuries. New York: Cambridge University Press.

Knodel, J. 1986. Demographic Transitions in German Villages. In The Decline of Fertility in Europe, edited by A. Coale and S. Watkins, Princeton: Princeton University Press. Pp. 337-389.

Knodel, J. 1974. The Decline of Fertility in Germany, 1871-1939. Princeton: Princeton University Press.

Livi Bacci, M. 1971. A Century of Portuguese Fertility. Princeton: Princeton University Press.

Livi Bacci, M. 1968. "Fertility and nuptiality changes in Spain from the late $18^{\text {th }}$ to the early $20^{\text {th }}$ century." Population Studies, 22(1): 83-102; and 22(2): 211-234. 
Sánchez-Barricarte, J.

Reher, D. S. 1990. Town and Country in Pre-industrial Spain. Cuenca, 15501870. Cambridge: Cambridge University Press.

Reher, D. S. 1988. Familia, población y sociedad en la provincia de Cuenca. 1700-1970. Madrid: CIS.

Manuscript Received February 2000; Manuscript Revised January 2001 
A New Proposal for Measuring Marital Fertility in Historical Populations

Appendix 1a

Results of Simulation in a Hypothetical Population

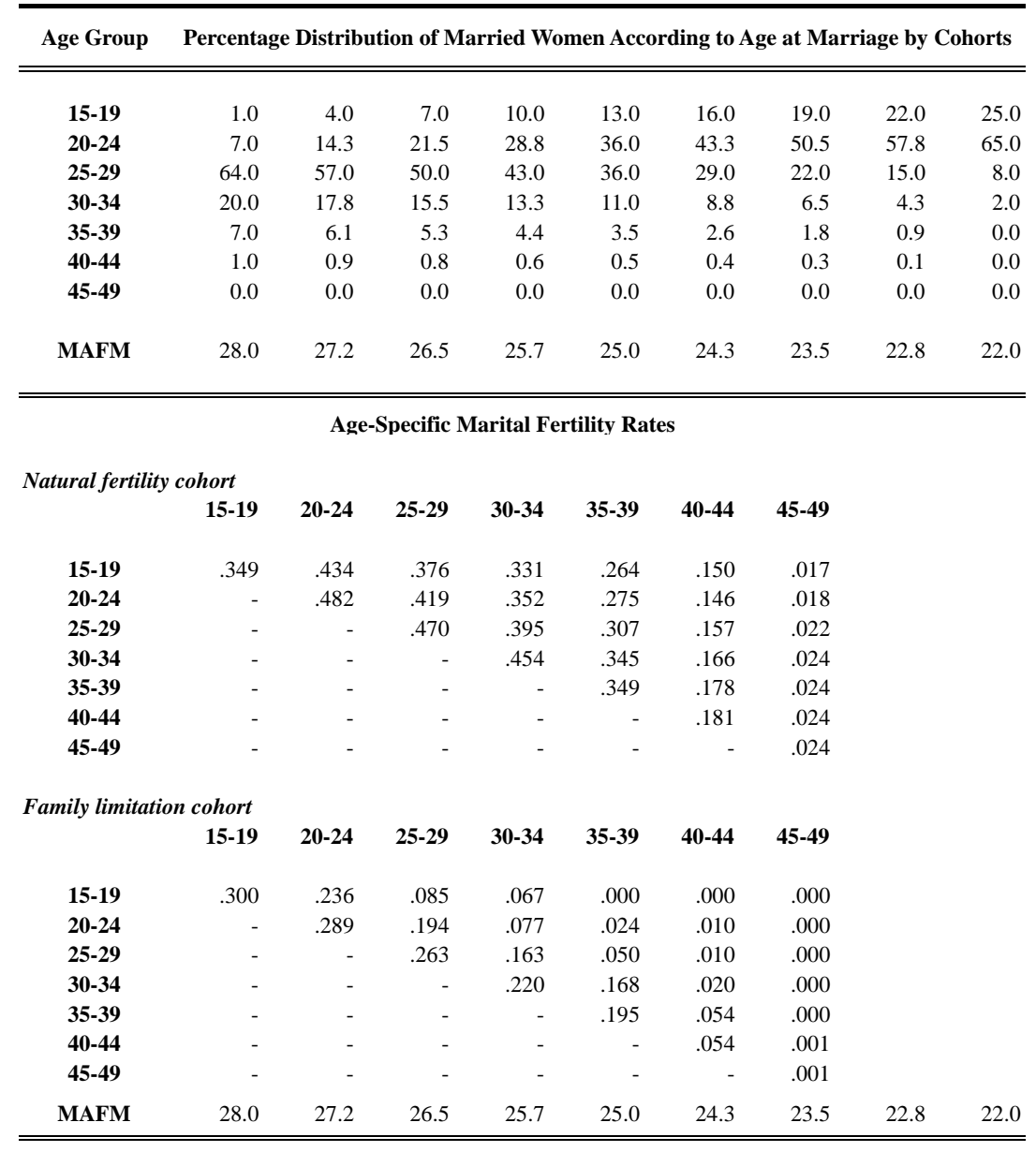


Sánchez-Barricarte, $J$.

Appendix 1b

Results of Simulation in a Hypothetical Population.

\begin{tabular}{|c|c|c|c|c|c|c|c|c|c|}
\hline Indices & \multicolumn{9}{|c|}{ Scenario 1: Natural Fertility and Low Mortality } \\
\hline TMFR & 9.20 & 9.07 & 8.96 & 8.85 & 8.75 & 8.65 & 8.56 & 8.47 & 8.38 \\
\hline I'g & 0.85 & 0.83 & 0.82 & 0.81 & 0.80 & 0.79 & 0.78 & 0.77 & 0.76 \\
\hline NImr & 5.40 & 5.68 & 5.90 & 6.16 & 6.34 & 6.60 & 6.88 & 7.11 & 7.40 \\
\hline Family size & 5.48 & 5.72 & 5.96 & 6.20 & 6.44 & 6.67 & 6.91 & 7.14 & 7.37 \\
\hline Indices & \multicolumn{9}{|c|}{ Scenario 2: Natural Fertility and High Mortality } \\
\hline TMFR & 9.20 & 9.07 & 8.96 & 8.85 & 8.75 & 8.65 & 8.56 & 8.47 & 8.38 \\
\hline I'g & 0.85 & 0.83 & 0.82 & 0.81 & 0.80 & 0.79 & 0.78 & 0.77 & 0.76 \\
\hline NImr & 5.05 & 5.29 & 5.49 & 5.71 & 5.87 & 6.09 & 6.33 & 6.54 & 6.78 \\
\hline Family size & 5.10 & 5.32 & 5.52 & 5.73 & 5.94 & 6.14 & 6.34 & 6.55 & 6.75 \\
\hline Indices & \multicolumn{9}{|c|}{ Scenario 3: Controlled Marital Fertility and Low Mortality } \\
\hline TMFR & 4.01 & 3.82 & 3.65 & 3.50 & 3.35 & 3.21 & 3.07 & 2.93 & 2.81 \\
\hline I'g & 0.36 & 0.34 & 0.32 & 0.30 & 0.29 & 0.27 & 0.26 & 0.24 & 0.23 \\
\hline NImr & 1.83 & 1.89 & 1.92 & 1.96 & 1.96 & 2.02 & 2.10 & 2.16 & 2.25 \\
\hline Family size & 1.92 & 1.98 & 2.04 & 2.09 & 2.13 & 2.18 & 2.21 & 2.25 & 2.28 \\
\hline Indices & \multicolumn{9}{|c|}{ Scenario 4: Controlled Marital Fertility and High Mortality } \\
\hline TMFR & 4.01 & 3.82 & 3.65 & 3.50 & 3.35 & 3.21 & 3.07 & 2.93 & 2.81 \\
\hline I'g & 0.36 & 0.34 & 0.32 & 0.30 & 0.29 & 0.27 & 0.26 & 0.24 & 0.23 \\
\hline NImr & 1.74 & 1.80 & 1.83 & 1.86 & 1.85 & 1.91 & 1.99 & 2.05 & 2.14 \\
\hline Family size & 1.83 & 1.88 & 1.93 & 1.97 & 2.02 & 2.06 & 2.10 & 2.13 & 2.17 \\
\hline
\end{tabular}

MAFM: Mean age at first marriage

TMFR: Total marital fertility rate (ages 20 to 49)

Note: The mean age at marriage in each age group is defined as follows:

$\begin{array}{ll}15-19 & 18.5 \\ 20-24 & 22.5 \\ 25-29 & 26.5 \\ 30-34 & 31.5 \\ 35-39 & 36.5 \\ 40-44 & 41.5 \\ 45-49 & 46.5\end{array}$


Appendix 2. Levels of mortality

\begin{tabular}{ccc}
\hline Age & High Mortality & $\begin{array}{c}\text { Low Mortality } \\
\mathbf{n q}_{\mathbf{x}}\end{array}$ \\
\hline \hline $\mathbf{\mathbf { n q } _ { \mathbf { x } }}$ & & \\
$\mathbf{0}$ & .1908 & .0164 \\
$\mathbf{1}$ & .2083 & .0027 \\
$\mathbf{5}$ & .0439 & .0016 \\
$\mathbf{1 0}$ & .0241 & .0014 \\
$\mathbf{1 5}$ & .0352 & .0017 \\
$\mathbf{2 0}$ & .0457 & .0021 \\
$\mathbf{2 5}$ & .0481 & .0027 \\
$\mathbf{3 0}$ & .0505 & .0035 \\
$\mathbf{3 5}$ & .0522 & .0053 \\
$\mathbf{4 0}$ & .0525 & .0080 \\
$\mathbf{4 5}$ & .0600 & .0129 \\
$\mathbf{5 0}$ & .0799 & .0195 \\
$\mathbf{5 5}$ & .1167 & .0310 \\
$\mathbf{6 0}$ & .1771 & .0479 \\
$\mathbf{6 5}$ & .2730 & .0813 \\
$\mathbf{7 0}$ & .4196 & .1416 \\
$\mathbf{7 5}$ & .5979 & .2624 \\
$\mathbf{8 0}$ & .7566 & .4206 \\
$\mathbf{8 5}$ & .8776 & .6126 \\
& & \\
\hline
\end{tabular}

